\title{
Why i chose a counseling career
}

Volume 2 Issue 4 - 2015

\section{Opinion}

$15 y e a r s$ ago I suffered a work-related injury, and it was during this time, I was informed by medical professionals that to keep my career I would have to undergo surgery. Unfortunately, one intervention led to another and after many operations I was left with a spinal instability. Associated with this, I was affected with constant sciatica down the right hand side of my body, which emanated in my lower lumbar vertebrate, and was referred, down my right leg to the toes on my right foot.

I was unable to walk. I couldn't perform daily activities such as washing and dressing my extremities, putting on shoes and socks, drive my car which I loved, or even leave my house unattended, all of which I had previously taken for granted, and now found that I was dependant on my family and friends to assist me in these tasks. Finally, I was then referred to a spinal specialist who explained that my condition necessitated an anterior and posterior lumbar fusion.

It was at this point I was made aware that after all I had been through; I was going to lose my job anyway. Once I had the operation, I was then made redundant. My future as I saw it was bleak and daily life was tough, especially with a young family of four children and no income, or even the prospect of getting a job, along with my condition deteriorating even though I was attending physiotherapy and pain management, to help with recovery.

My wife, who had given up her career when we got married to become a housewife, had no option but to return to work, to provide an income for us all, while I stayed at home. As for myself, I was in constant pain, to I was prescribed strong medication. However over time, I found that the medication became ineffective against the pain, which resulted in being prescribed opioids, again it was not long before I even developed a tolerance, and it was at this juncture I then started to look towards the combination of alcohol and opioids to alleviate the pain, and as far as I was concerned, nothing seemed to work effectively, all I wanted was for the pain to go away. On reflection, I can now look back at this time, and can only say that I was not living, but purely existing in a zombie state from one day to the next. Needless to say, I was depressed, but I did not even have the self-awareness or cognitive ability to recognize this fact, and even discounted the views and remarks of others who implied that I was depressed.

The above continued for five years. I have often since listened to my patients describing to me that they feel as though they were stuck in a long dark tunnel with no end in sight, I guess you could say I was there. Christmas 1995 I remember all too well, a day of taking pain killers and drinking red wine, to the point I made a complete and utter fool of myself, more so than usual, and upset my youngest daughter by my behavior, upset her so much, it was enough of a kick up the bottom I needed to finally sort myself out, I could not carry on that way, as there would become a point my family would have had enough, and then I would really have nothing.

As a family we sat down and talked, it was at this point I was made aware just how upset others were not only in regards my condition,

\section{Paul Mallott}

Pulse, UK

Correspondence: Paul Mallott, Counselor, Pulse, UK, Email counselor.mncs@sky.com

Received: December 19, 2014 | Published: April 06, 2015

but my health and behavior as well, all of which I had been Blind too. The path I had chosen up until then was to let my pain have the control over my life. I decided then and there, I'd had enough. I would rather have the pain than the side-effects of medication and alcohol and ongoing interventions that failed to provide any improvement. If there was to be improvement it was down to me to find that way.

My mind was still active, even if my body was not. So I decided to return to education and learn another career. It had to be one which would not be influenced by my physical condition. For myself, counseling seemed a natural choice, as in the past many individuals had always approached me for my help, when they had problems, I always found that others seem to be able to be open and talk to me freely about their problems.

I then spent the coming years learning various forms of psychological therapies and engaged in counseling training. To my surprise I soon found that focussing on learning, was distracting me from concentrating on my pain. The more I kept my mind occupied with thinking about something other than the pain, the less the pain was impacting on me, of course I still had pain, it never went away, but its significance to me, and the fact I had constantly focussed on it previously had gone, in effect I had change my thinking, from dwelling on the pain, how I felt about it, how I felt about myself and so on, to concentrating on other things, and started to live with the pain, rather than the pain control me, I would challenge the pain, to see what activities I could do and for how long I could do these activities without aggravating the pain further, making it worse, I was learning to pace myself, reduce medication. I will mention this change did not happen overnight, it took considerable time to master this technique, along with many other skills I had to learn and areas in which I had to make changes, such as sleep, relaxation using various cognitive skills, distraction and mindfulness tools, and thought management. Finally I reached a stage whereby the pain, depression no longer interfered with my well-being, and psychologically, physically and socially I was improved. I stopped all pain medication, stopped drinking and stopped further medical interventions. 
It is now after all these years, I now give back all that I've learned during my life experience and acquired learning to help others. My service-users' feedback tells me I've made the right decision. I'm always encouraged by comments like, 'finally someone who listens to what I have to say' and 'your help and intervention has been invaluable'. This feedback is what drives me and keeps me going. Knowing that I am making a difference to the lives of others and that I am there for the individual is inspiring. I'm not motivated by financial reward or targets. Helping others is my reward and motivation.

At this present time I work as a Counsellor/Cognitive Behavioural specialist delivering face-to-face and group support to a diverse range of individuals who are affected with chronic pain and associated mental health barriers.

My own life demonstrated to me that as an Individual, and prior to my decline in health, I was capable of dealing with day-to-day problems using my own methods and skills which I had learned throughout life. However, at the point of my injury and subsequent behaviour, the methods I had used to employ were just no longer effective. I became trapped in a cycle of negative thoughts and emotions which then affected my behaviour.

Having since learned and used Cognitive Behavioural Therapy, I strongly believe this is evidence based fact, as I have experienced this personally myself, and the work of Beck (1991) and also Ellis (1998) demonstrates this. Working in pain management, I also became aware of 'Gate Theory' which proposes that the pain signal transmission can be influenced by emotions and thoughts. It is well known that people do not feel a chronic pain or, to be more appropriate, the pain does not disturb them when they concentrate on other activities that interest them. Whereas, people who are anxious or depressed feel intense pain and find it difficult to cope up with it. This is because the brain sends messages through descending fibres that stop, reduce or amplify the transmission of pain signals through the gate, depending on the thoughts and emotions of a person. This theory has also paved way for more research on cognitive and behavioural approaches to achieve pain relief. It is a theory I had been practicing myself, on myself for many years without even knowing it.
I now teach the individual new cognitive skills, I give them a toolbox that they can use to help them manage their pain and issues more effectively, thereby hopefully, helping them to break the cycle of negativity to which they are trapped For the majority of individuals this form of intervention has proved effective, however we are all individual and as such there are those, who are unable to appreciate the benefits of such an intervention, they simply cannot believe how just CBT or even talking therapy can help manage their pain and condition, a common reply is, 'since when has talking or learning, ever achieved anything, my pain is real, it is not in my head'. No amount of talking, explaining or using empathy has changed their minds; they simply want and demand medical intervention.

I am always learning and reflecting on practice to improve my delivery and effectiveness at helping others, in regards the latter, I am now looking at new ways to change delivery to overcome the above barrier, but at the same time, have awareness, that there are those even in counseling you are unable to be effective for, you cannot help everybody, or achieve positive results all of the time, it is a demand and un-realistic. In 2013 I was awarded a National and Regional Award for Healthcare practice and learning. Through my own difficulties I've found a new and rewarding career path which I enjoy immensely. I can think of no better motivation than to help others.

\section{Acknowledgments}

None.

\section{Conflicts of interest}

Author declares there are no conflicts of interest.

\section{Funding}

None. 